\title{
Attendance Feedback In An Academic Setting: Preliminary Results
}

Willard G. Broucek, (Email: broucekw@northern.edu), Northern State University William Bass, Northern State University

\begin{abstract}
In the fall of 2005, the attendance behavior of 118 business students at Northern State University (NSU) was monitored in 4 classes. After 10 weeks of classes Absenteeism Feedback was given to these students. Examination of the data indicated a strong correlation between attendance and subsequent course grade.
\end{abstract}

\section{BACKGROUND}

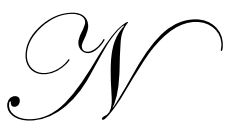

umerous variables are important in predicting academic success in college. Student ability, operationalized by standardized measures such as ACT scores, and prior academic performance, such as high school rank, have been shown to be strong predictors of college success as every post-secondary admissions office can attest (Covington, 1992; Willingham, Lewis, Morgan, \& Ramist, 1990). As well, motivational variables such as achievement goals (Harachiewicz, Barron, Tauer, \& Elliot, 2002); personality variables such as the Big Five (Okun \& Finch, 1998) and Academic Hardiness (Benishek \& Lopez, 2001); and values such as intellectualism (Hertel, 2002) have been shown to be related to academic success. Attendance is also considered to be a major component of academic success.

The purpose of this research project was to examine the efficacy and feasibility of increasing classroom attendance through employing the technique of Absenteeism Feedback (Gaudine \& Saks, 2001). Moore (2002) demonstrated that there is a strong correlation of high class attendance with high grades as well as of poor class attendance with low grades in situations where students do not receive points for attending. The problem is, thus, one of increasing class attendance without making it compulsory.

Gaudine and Saks (2001) demonstrated that Absenteeism Feedback Intervention, whereby individuals were jointly informed about the number of days during a given period that they were absent as well as the average number of days that their peers were absent during that same period, significantly reduced subsequent absenteeism among individuals with higher than average absenteeism.

The rationale for Absenteeism Feedback Intervention is that most people have a "self-serving bias" in which they underestimate their own absenteeism and overestimate the absenteeism of their coworkers (Johns, 1994). When people receive feedback documenting their absences as well as the average number of absences during the same period by their co-workers, their attendance improves. The question is - Will Absenteeism Feedback work in the university classroom?

The effects of Absenteeism Feedback on student attendance behavior has never been examined in the literature. Gaudine and Saks (2001) found that employee Absenteeism Feedback in a hospital setting significantly improved attendance of hospital employees. Whether providing students with a summary of their attendance and the average attendance of their classroom peers will decrease absenteeism in students is an open, empirical question that merits investigation. It is hypothesized that attendance will increase after receipt of the feedback letter. 


\section{METHODOLOGY}

The attendance of 162 of business students in upper division business courses was monitored each class period. Ninety six students were female, while sixty-six were male.

One author utilized a sign-in sheet which was passed out each class period. The other author enlisted one student in each class to keep a record of attendance in each class. Attendance sheets were given to work studies who entered the data on a spreadsheet.

At the beginning of the eighth week of the semester students were given an individual letter which indicated the number of days that they were absent and the percentage of days that they were absent. As well, they were informed how many days their classmates on average were absent as well as the percentage absences on average for their class. Students were informed that this information was for informational purposes and that there were no consequences regarding their absences.

Attendance continued to be monitored for the remainder of the semester but no further feedback was given.

\section{RESULTS}

One.

Results of the relationship between pre and post feedback attendance and course GPA are given in Table

Table 1

Correlation Matrix

\begin{tabular}{lllc}
\hline & $\mathbf{1}$ & $\mathbf{2}$ & $\mathbf{3}$ \\
\hline 1. Attendance Pre & -- & $69^{* *}$ & $53^{* *}$ \\
2. Attendance Post & & -- & $70^{* *}$ \\
3. Course GPA & & -- \\
\hline $\mathrm{p}<.05, * * \mathrm{p}<.01 ., * * * \mathrm{p} .001$ & &
\end{tabular}

It is evident that course GPA was significantly correlated with attendance. However, it was noted that attendance did not improve subsequent to the letter. Rather as demonstrated by the significant correlation between pre and post letter attendance, attendance appeared to be unchanged by the receipt of the letter comparing individual attendance to peer attendance.

\section{DISCUSSION}

Course GPA was shown to be significantly correlated with attendance. The strength of the relationship appeared to be stronger the last third of the semester subsequent to the letter. Nonetheless this study illustrates the important relationship between attendance and classroom performance.

The fact that attendance did not appear to be positively affected by the feedback letter was contrary to hypothesis. One reason for this may be that it was given relatively late in the semester, i.e., it was given too late to allow for a change in behavior. Another possibility was that students whose attendance was better than average may have decided to even things out a bit by taking a few days off.

A replication of the study should attempt to give the feedback letter earlier.

The major finding was that grades were strongly linked to attendance. Though this is what most faculty assume, it is good to have the importance of attendance documented. 


\section{BIBLIOGRAPHY}

1. Benishek, L. A. \& Lopez, F. G. (2001). Development and initial validation of a measure of academic hardiness. Journal of Career Assessment, 9, 333-352.

2. Brophy, J. E. (1983). Conceptualizing student motivation. Educational Psychologist, 18, 200-215.

3. Covington, M. V. (1992). Making the grade: A self-worth perspective on motivation and school reform. New York: Cambridge University Press.

4. Digman, J. M. (1990). Personality structure: Emergence of the five-factor model. In M. R. Rosenzweig \& L. W. Porter (Eds.), Annual Review of psychology, 41, 417-440, Palo Alto, CA: Annual Reviews.

5. Harackiewicz, J. M., Barron, K. E., Tauer, J. M., \& Elliot, A. J. (2002). Predicting success in college: A longitudinal study of achievement goals and ability measures as predictors of interest and performance from freshman year through graduation. Journal of Educational Psychology, 94, 562-575.

6. Costa, P. T., \& McCrae, R. R., (1992). NEO-PI-R Professional manual. Odessa, FL: Psychological Assessment Resources Inc.

7. Elliot, A. J., \& Church, M. A. (1997). A hierarchical model of approach and avoidance achievement motivation. Journal of Personality and Social Psychology, 72, 461-475.

8. Forsterling, F. \& Binser, M. J., (2002) Depression, schol performance, and the veridicality of perceived grades and causal attributions. Personality and Social Psychology Bulletin, 28, 1441-1449.

9. Hertel, J. B. (2002). College student generational status: Similarities, differences, and factors in college adjustment. The Psychological Record, 52, 3-18.

10. Judge, T. A., Thoresen, C. J., Bono, J. E., \& Patton, G. K. (2001). The job satisfaction-job performance relationship: A qualitative and quantitative review. Psychological Bulletin,27,376-407.

11. McCrae, R. R., \& Costa, P. T. (1987). Validation of the five-factor model of personality across instruments and observers.

12. Okun M. A. \& Finch, J. F. (1998). The big five personality dimensions and the process of institutional departure. Contemporary Educational Psychology, 23, 233-256.

13. Sinclair, R. R. \& Tetrick, L. E. (2000). Implications of item wording for hardiness structure, relation with neuroticism, and stress buffering. Journal of Research in Personality, 34, 1-25.

14. Willingham, W.W., Lewis, C., Morgan, R., \& Ramist, L. (1990). Predicting college grades: An analysis of institutional trends over two decades. Princeton, NJ: Educational Testing Service. 


\section{APPENDIX}

\section{Absenteeism Information}

Dear Student:

We are planning to study absenteeism over the next few semesters. To begin this review, we are providing students with feedback about their absenteeism.

Our feedback will begin with this semester and will continue next year. Please be assured that while faculty would like to decrease avoidable absence days, we do not wish students to attend when they are sick.

The following definition will help you to interpret your feedback.

(1) Total number of absent days - This includes all classes you missed in BADM 424.

(2) Percent number of absent days - This represents the percent of classes that you missed in BADM 424.

We wish to provide you with the following data from our records:

(1) Your total number of absent days this semester for BADM 424 from Aug. 30, 2005 to Oct. 26, 2005 was: 5

(2) The average number of absent days this semester for BADM 424 of your classmates from Aug. 30, 2005 to Oct. 26, 2005 was: $\quad .87$

(3) Your percentage of absent days this semester for BADM 424 from Aug. 30, 2005 to Oct. 26, 2005 was: $71 \%$

(4) The average percentage of absent days this semester for BADM 424 of your classmates from Aug. 30, 2005 to Oct. 26, 2005 was: 13 $\%$

Again, please be assured that while faculty would like to decrease avoidable absent days, we do not wish people to come to school when they are sick.

Sincerely,

Willard Broucek, Ph.D. 